\title{
Morphological and Biometrical Characterization of Seeds of Some Algerians Lentil Accessions: Quantitative and Qualitative Characters
}

\author{
GAAD D. ${ }^{1,2, *}$, Laouar M. ${ }^{2}$, Abdelguerfi $A^{2}$ \\ ${ }^{1}$ Department of Agriculture and Biotechnology, National Research Center for Biotechnology, Constantine, Algeria \\ ${ }^{2}$ Department of Phytotchnie, National School for Agriculture, Algiers, Algeria \\ *Corresponding author: d.gaad@crbt.org
}

Received August 04, 2014; Revised August 16, 2014; Accepted August 24, 2014

\begin{abstract}
The preliminaries characterization of a collection of twenty three Algerians accessions of lentil (Lens culinaris M.) were done before sown. Seed thickness (STH), Seed diameter (SDM), thickness/diameter ratio (T/D) and Weight of 100 seeds (WHS), are a quantitative traits measured. Altitude and Rainfall of location of origin of accessions are considered as a supplement variables. Also, qualitative characters: Grain form (GFR), Ground color of seed testa (GCT), Pattern of testa (PAT), Cotyledons color (COC), were considered. From the result of Principal Component Analysis (PCA), axis 1 explains $65.08 \%$ of the variance in the qualitative character and it showed a strange negative correlation with seed diameter (SDM), Weight of 100 seeds (WHS) and altitude (ALT).Whereas, it was positively and significantly correlated with thickness/diameter ratio (T/D) variable. The second component, accounting for $23.58 \%$ of the total variation, was correlated positively with seed thickness (STH). Hierarchical discriminate analysis revealed major differences between accessions from different regions. Three major regional groups were apparent: 1) a Western group characterized by accessions of the Macrosperma type, 2) a more Northern group of the Microsperma type and 3) A mixture group gathered all regions and the two types. Regarding qualitative traits, the application of Multiple Correspondence Analyses (MCA) showed that seeds with globular form (Microsperma) are two types: 1) Brown or green tasta with dotted seed coat pattern or note and yellow cotyledons and 2) Brown tasta with orange cotyledons. In addition, seeds with flat form (Macrosperma) are divided into two types: 1) Brown, Beige or Green tasta with yellow cotyledons, 2) Brown tasta with dotted seed coat pattern and yellow cotyledons.
\end{abstract}

Keywords: Lens culinaris, quantitative traits, qualitative characters, Microsperma, Macrosperma

Cite This Article: GAAD D., Laouar, M. and Abdelguerfi A, "Morphological and Biometrical Characterization of Seeds of Some Algerians Lentil Accessions: Quantitative and Qualitative Characters.” World Journal of Agricultural Research, vol. 2, no. 4 (2014): 183-186. doi: 10.12691/wjar-2-4-8.

\section{Introduction}

Among pulses, lentil (Lens culnaris M.) is one of the most important grain legume consumed by Algerians population [1]. Where its seed is an important local dietary item rich in protein $[4,16]$. However, yield instability at different locations and among seasons has been recognized as a persistent problem [13]. This is due to many causes. Including the absence of a local germoplasme evaluation data, regarding desirable traits of seeds. Which is a very important step, in identification of better genotypes, which can be helpful for successful breeding program.

Numerous studies have been conducted in this subject area and most of the studies have been largely focus on phenological and vegetative characters, such as: Time to flower day, plant height, number of pods per plant, number of seed per pods, seed yield, time to maturity, etc. $[2,8,10,11,15,17]$. On the other hand, there is limited research regarding seed characters evaluation $[3,12,18,19]$.
The objective of this study, were to investigate the relationships between the important characters of seeds (quantitative and qualitative) on the basis of location of origin of accessions.

\section{Materiel and Method}

\subsection{Plant Materiel}

The vegetal material consisted of thirty two lentil accessions originating from differences localities of Algeria. Lentil accessions within each region were collected in 2011. Relevant passport data of populations are given in Table 1.

\subsection{The Methods}

To determine average seed size, 20 seeds were randomly picked from each accessions and their two dimensions (diameter (SDM) and thickness (STH) were 
measured using a digital caliper with an accuracy of 0.01 $\mathrm{mm}$. For the same seeds, qualitative characters: Grain form (GFR), Ground color of seed testa (GCT), Pattern of testa (PAT) and Cotyledons color (COC) were examined by visual method. 100-seed weight (WHS) was determined using an electronic balance to an accuracy of $0.001 \mathrm{~g}$.

Table 1(a). List of thirty two (32) lentil genotypes and Agro climatic characteristics of the location of origin

\begin{tabular}{|c|c|c|c|c|}
\hline Genotypes & Site & Lat. & Long. & Alt. \\
\hline ALG1 & El-Khroub & 35.25 & 6.61 & 675 \\
\hline ALG2 & El-Khroub & 36.28 & 6.67 & 560 \\
\hline ALG3 & Yakouren & 36.73 & 4.43 & 1252 \\
\hline ALG4 & Azazga & 36.56 & 4.45 & 1147 \\
\hline ALG5 & Mila & 36.45 & 6.26 & 486 \\
\hline ALG6 & Dahmouni & 35.33 & 1.90 & 1083 \\
\hline ALG7 & Dahmouni & 35.45 & 1.41 & 995 \\
\hline ALG8 & Dahmouni & 35.45 & 1.73 & 908 \\
\hline ALG9 & Dahmouni & 35.37 & 1.31 & 995 \\
\hline ALG10 & Hassi-Zahan & 35.11 & 0.38 & 483 \\
\hline ALG11 & Malza & 35.19 & -0.64 & 470 \\
\hline ALG12 & Ain Trid & 35.10 & -0.63 & 483 \\
\hline ALG13 & Benchiba & 34.83 & -0.50 & 485 \\
\hline ALG14 & Merine & 35.19 & -0.63 & 476 \\
\hline ALG15 & El-Maleh & 35.28 & 1.08 & 224 \\
\hline ALG16 & Agllal & 35.30 & -1.14 & 250 \\
\hline ALG17 & Bouskine & 36.26 & 2.45 & 981 \\
\hline
\end{tabular}

Table 1 (b). List of thirty two (32) lentil genotypes and Agro climatic characteristics of the location of origin

\begin{tabular}{|c|c|c|c|c|}
\hline Genotypes & Site & Lat. & Long. & Alt. \\
\hline ALG18 & Bouskine & 36.08 & 2.75 & 981 \\
\hline ALG19 & Bouskine & 36.08 & 3.00 & 1005 \\
\hline ALG20 & Bouskine & 36.08 & 3.00 & 1005 \\
\hline ALG21 & Bouskine & 36.08 & 3.00 & 1005 \\
\hline ALG22 & Bouskine & 36.08 & 3.00 & 1005 \\
\hline ALG23 & Bouskine & 36.08 & 3.00 & 1005 \\
\hline ALG24 & Bir Aghbalo & 36.25 & 4.17 & 1005 \\
\hline ALG25 & El-Khroub & 36.33 & 6.66 & 694 \\
\hline ALG26 & Bir Ayad & 36.22 & 3.36 & 525 \\
\hline ALG27 & Ridden & 35.35 & 3.53 & 500 \\
\hline ALG28 & Khbouzia & 36.38 & 3.90 & 530 \\
\hline ALG29 & Illoula & 36.71 & 4.05 & 264 \\
\hline ALG30 & Ifigha & 36.71 & 4.04 & 225 \\
\hline ALG31 & Janet & 24.33 & 9.29 & 1050 \\
\hline ALG32 & Beni Fouda & 36.09 & 5.26 & 1100 \\
\hline
\end{tabular}

\subsection{Statistical Analysis}

Data were subjected to differences statistical analysis: For all characters, descriptive statistics were calculated, together with Pearson correlation coefficient.

Principal Component Analysis (PCA) on the average standardized values was also carried out to study the relationship between quantitative characters, followed by cluster analysis with the CLUSTER procedure using the Ward's minimum variance hierarchical method.

Qualitative characters were analyzed by Multiple Analyze of Correspondence (MCA).

Statistical analyses were made with the XLSTAT 2011 statistical program (version 13.02.05).

\section{Results and Discussion}

\subsection{Descriptive Statistics and Analysis of Correlations (Pearson (n))}

Table 1 gives the size (SDM, STH and T/D) and the weight (WHS) distribution of the lentil seeds. The diameter seeds varied from $2.3 \mathrm{~mm}$ to $6.90 \mathrm{~mm}$ with an average mean of $4.5 \pm 1.83$ and seeds thickness ranging from $1.56 \mathrm{~mm}$ to $2.90 \mathrm{~mm}$ with an average mean of $2.48 \pm 0.34$. Regarding 100 seeds weight, it varied from $3.00 \mathrm{~g}$ to 6.94 with an average mean of $5.15 \pm 1.1$.

These observations are in agreement with previous related studies. In fact, [9], reported that, the mean diameter and thickness of lentil were 4.45-6.82 and 2.36$2.55 \mathrm{~mm}$ respectively.

Table 2. The average seed size (Diameter, thickness and thickness /diameter ratio), weight of 100 seeds and standard deviation data from 32 observations

\begin{tabular}{|c|c|c|c|c|}
\hline Variable & Min & Max & Mean & SD \\
\hline SDM (mm) & 2.393 & 6.931 & 4.588 & 1.837 \\
\hline STH (mm) & 1.566 & 2.906 & 2.489 & 0.341 \\
\hline T/D & 0.248 & 1.197 & 0.669 & 0.338 \\
\hline WHS(g) & 3.000 & 6.940 & 5.150 & 1.127 \\
\hline
\end{tabular}

Table 3 shows Pearson correlation coefficients among quantitative characters; SDM and WHS were positively and significantly correlated. While, STH it was positively and significantly correlated with T/D. SDM was negatively and significantly correlated with STH and TD. Whereas, WHS was only negatively and significantly correlated with STH. Altitude was positively and significantly correlated with SDM and negatively and significantly correlated with T/D. However, rainfall was not correlated significantly with any of these characters.

Table 3(a).Correlation between characters with Pearson correlation coefficient of 0.05

\begin{tabular}{|c|c|c|c|c|c|c|}
\hline Variables & SDM & STH & T/D & WHS & ALT & RFL \\
\hline SDM & 1 & -0.355 & -0.968 & 0.564 & 0.364 & 0.304 \\
\hline STH & -0.355 & 1 & 0.528 & -0.077 & -0.221 & -0.280 \\
\hline
\end{tabular}

Table 3(b). Correlation between characters with Pearson correlation coefficient of 0.05

\begin{tabular}{|c|c|c|c|c|c|c|}
\hline Variables & SDM & STH & T/D & WHS & ALT & RFL \\
\hline T/D & -0.968 & 0.528 & 1 & -0.482 & -0.375 & -0.277 \\
\hline WHS & 0.564 & -0.077 & -0.482 & 1 & 0.053 & 0.217 \\
\hline ALT & 0.364 & -0.221 & -0.375 & 0.053 & 1 & 0.332 \\
\hline RFL & 0.304 & -0.280 & -0.277 & 0.217 & 0.332 & 1 \\
\hline
\end{tabular}

Regarding qualitative traits, wide variability was observed for all of the characters among the thirty two lentil accessions (Table 3). Flat and Globular (GFR) types of seeds were found in $71.87 \%$ and $28.12 \%$ respectively. Color of seed coat (CSC) varied from normal brown (78.12\%) and green (15.62\%) to Beige (6.25\%).Yellow cotyledon was shown by $90.62 \%$, while orange and green was shown by $6.25 \%$ and $3.12 \%$ of the accessions respectively. $90.62 \%$ of accessions did not show any seed coat pattern (SCP), however, seed coat pattern with spots was found in $6.25 \%$ accessions and dotted seed coat pattern was shown by only $3.12 \%$.

\subsection{Multivariate Analysis}

\subsubsection{Principal Components Analysis}

Table 4 shows relative and per cent proportions of the total variance for each of the first two principal components, the calculated eigenvalues and the coefficient of correlations between the principal components (PC1 and PC2) and the original variables; these coefficients indicate the contribution of each trait to the formation of PC1 and PC2. 
Table 4. Effectives and percent (\%) of qualitative characters

\begin{tabular}{|c|c|c|c|}
\hline Variables & Modalities & Effectives & $\%$ \\
\hline \multirow{3}{*}{ FRG } & Globular & 9 & 28.125 \\
\cline { 2 - 4 } & Flat & 23 & 71.875 \\
\hline \multirow{3}{*}{ PAT } & Dotted & 1 & 03.125 \\
\cline { 2 - 4 } & without & 29 & 90.625 \\
\cline { 2 - 4 } & Spotted & 2 & 06.250 \\
\hline \multirow{3}{*}{ GTC } & Beige & 2 & 06.250 \\
\cline { 2 - 4 } & Green & 5 & 15.625 \\
\cline { 2 - 4 } & Brown & 25 & 78.125 \\
\hline \multirow{3}{*}{ COC } & Yellow & 29 & 90.625 \\
\cline { 2 - 4 } & Orange & 2 & 06.250 \\
\cline { 2 - 4 } & Green & 1 & 03.125 \\
\hline
\end{tabular}

Table 5. Eigenvalues of the Correlation Matrix

\begin{tabular}{|c|c|c|c|c|}
\hline & F1 & F2 & F3 & F4 \\
\hline Eigenvalues & 02.588 & 00.943 & 00.457 & 00.011 \\
\hline Proportion (\%) & 64.710 & 23.576 & 11.437 & 00.276 \\
\hline \%Cumulative & 64.710 & 88.286 & 99.72 & 100.00 \\
\hline
\end{tabular}
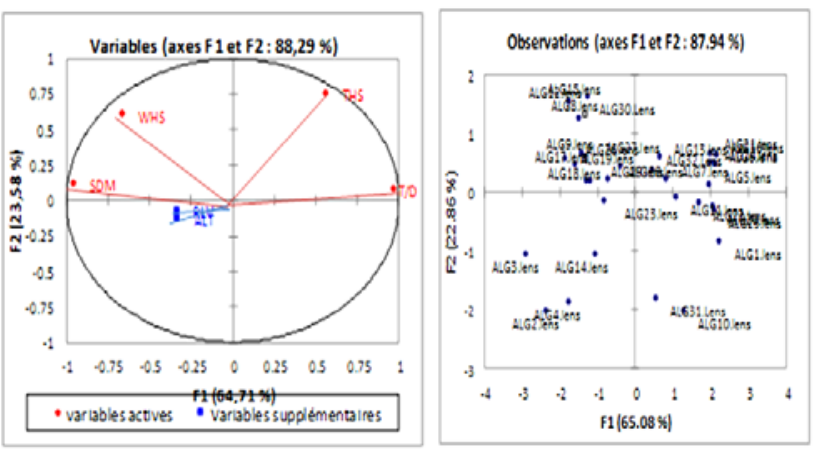

Figure 1. Principal components analysis (PCA) for variables $\{a\}$ and observations $\{b\}$. Amount of variance captured by axes 1 and 2 is shown

Eigenvalues of the first two principal components were greater than 1 and accounted for $88.28 \%$ of variance. PCA axis 1 explains $64.71 \%$ of the variance in the qualitative character, and is related in the negative side to seed size (SDM) and Weight of 100 seeds (WHS) and Altitude (ALT). And in the positive side to diameter /thickness ratio (T/D). Accessions with the strongest positive scores along this axis present a high E/D (ALG1, ALG5, ALG6, ALG16, ALG20, ALG21, ALG22, ALG24 and ALG25. A small seeded type they may have a globos shape (Microspema) with thickness / diameter ratio higher than 1 . Most of the other accessions (ALG3, ALG9, ALG7, ALG11, ALG17, ALG18, ALG23, ALG28, ALG29, ALG27 and ALG26) have negative scores on axis 1, this mean, that they have a small diameter and a light weight (Microsperma) and are originating from the low altitude.

As stated by [2], the cultigen lentil is divided by Barulina (1930) in two subspecies on the basis of seed size and seed weight: Macrosperma (large seeded with seed diameters between 6 and $9 \mathrm{~mm}$ ) with the 100 seed weight range from 4 to $2.8 \mathrm{~g}$, and Microsperma (small seeded with seed diameters between 4 and $6 \mathrm{~mm}$ ) generally have a range from 1.1 to $4 \mathrm{~g}$.

The second component, accounting for $23.57 \%$ of the total variation, was correlated positively with seed thickness (THS). This mean that, all populations on the side present, a big thickness (Microsperma).It's the case of following accessions: ALG8, ALG12, ALG13, ALG15, ALG19, ALG30 and ALG32. The other populations from the negative side of the PC2 axis (ALG2, ALG4, ALG10, ALG14 and ALG31) present a small thickness.

No attempt was made to interpret other PCA axes because they explained little additional variance (the eigenvalues for axes 3 and 4 were 0.457 and 0.011 , respectively).

\subsubsection{Cluster Analysis}

To study and categorize the studied accessions, Ward method was used in cluster analysis (Similarity index $=0.38$ based on assessed traits in six groups. Specifications for each cluster are presented below:

First group comprises 3 genotypes: ALG11, ALG7 and ALG13. These accessions present a short diameter and light 100 seed weight, they belong to the Microsperma type and all of them are originating from the west of Algeria.

Second group contains 7 genotypes: ALG1, ALG20, ALG25, ALG5, ALG22, ALG6, and ALG21, present a high thickness / diameter ratio of the type Microsperma. Native from East, North and West.

Third group included 2 genotypes: ALG10, ALG31, both are Macrosperma and originating from West and south of Algeria respectively.

Fourth group comprised 4 genotypes: ALG32, ALG23, ALG19, and ALG28, from the north expect ALG32. They have a small diameter and a light weight (Microsperma).

Group five: ALG14, ALG2, and ALG4, all of them are Macrosperma with a small thickness.

Group six comprises 11 genotypes: ALG3, ALG17, ALG26, ALG18, ALG9, ALG29, ALG8, ALG15, ALG30, ALG12 and ALG27. Most of them are originating from west of Algeria of the type Microsperma.

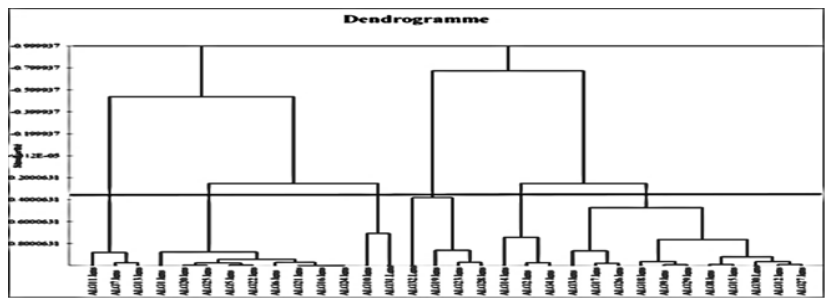

Figure 2. A Dendrogram for 32 accessions of lentil using Ward method

\subsubsection{Multiple Correspondence Analysis}

The application of multiple correspondence analysis showed that the total inertia explained is equal to 1.75 (percent of inertia: $50.87 \%$ is due to the first axis and $9.10 \%$ due to the second axis). A visualization of the results is presented in Figure 3. As we can see the profiles of Grain form (FRG): Flat (Macrosperma) an Globular (Microsperma) are quite different, as it was expected. In particular, presence of Brown or green tasta (CTG), with yellow cotyledons or orange (CDC), seems to characterize the globular form (Microsperma). On the other hand, seeds with flat form (Macrosperma) are characterized by: Brown, Beige or Green tasta (TGC) with dotted seed coat pattern or not (PAT) and yellow cotyledons (COC).

In lentil, the size of seeds increases from the types grown in eastern regions to western types. Two types, namely: Macrosperma, found mainly in the Mediterranean region and the New World (yellow cotyledons with little or no pigmentation), and Microsperma (with red orange or 
yellow cotyledons) found on the Indian subcontinent, Near East and East Africa, respectively, are known [14].

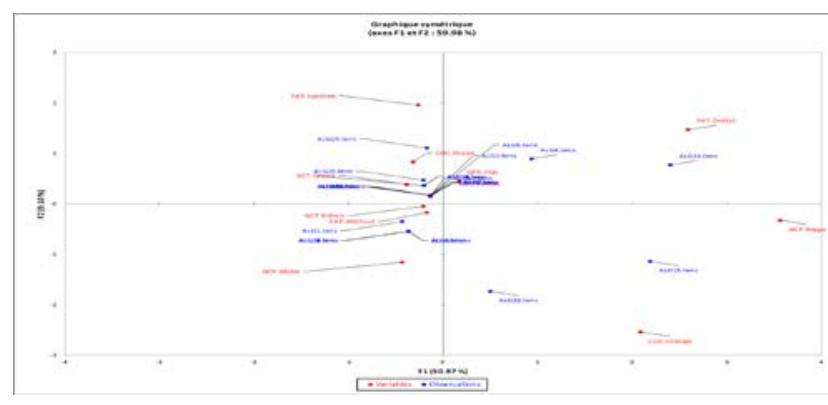

Figure 3. Multiple correspondence analysis of quantitative characters.

\section{Conclusion}

The results of this study revealed the presence of genetic variation in terms of quantitative traits and qualitative characters, among the studied of Algerians lentil seeds. It was possible to identify the most promising genotypes for inclusion in the lentil-breeding program.

\section{Acknowledgement}

I would like to thank the staff of Agriculture Technic Institute for providing me seeds of lentil.

\section{References}

[1] Abdelguerfi-Laouar,M., Hamdi N., Bouzid H., Zidouni F., Laib M. Bouzid L. and Zine F. "Les légumineuses alimentaires en Algérie : Situation, état des ressources phylogénétiques et cas du pois chiche à Bejaia”. in les actes des $3{ }^{\mathrm{em}}$ journées scientifiques de l'INRAA sur l'agriculture de montagne : développement régional et régionalisation de la recherche, Bejaia les 11, 12,13, avril 2001, 171-189.

[2] Bicer B. and Sakar D. "Studies on Variability of Lentil Genotypes in Southeastern Anatolia of Turkey," Not. Bot. Hort. Agrobot. Cluj 36 (1) 2008, 20-24.

[3] B.T. Biçer, "The effect of seed size on yield and yield components of chickpea and lentil,” African Journal of Biotechnology, 8 (8), Jun 2009. [Online]. Available at http://www.academicjournals.org/AJB
[4] Cicerali, I. N, Effect of salt stress on antioxidant defense systems of sensitive and resistant cultivars of lentil (Lens culinaris M.), Master of science, Middle East technical university, 2004, 90p.

[5] Cubero, J.I, Origin, domestication and evolution. In: Webb, C. and Hawtin, G.C. eds Lentils. Commonwealth Agricultural Bureau, Slough, UK, 1981, 15-38.

[6] Fogg, B.J, Persuasive technology: using computers to change what we think and do, Morgan Kaufmann Publishers, Boston, 2003, 3035.

[7] Hirsh, H., Coen, M.H., Mozer, M.C., Hasha, R. and Flanagan, J.L, "Room service, AI-style," IEEE intelligent systems, 14 (2). 8-19. Jul. 2002.

[8] Erskine W., Adham Y., and Holly L, "Geographic distribution of variation in quantitative traits in a world lentil collection," Euphytica, (43). 97-103, 1989.

[9] Fasina, O., Tyler, B., Pickard, M., Zheng, G.H. and Wang, N. "Effect of infrared heating on the properties of legume seeds," International Journal of Food Science and Technology (36). 79-90

[10] Ferguson M.E., and Robertson L.D, "Morphological and phenological variation in the wild relatives of lentil," Genetic Resources and Crop Evolution, (46). 3-12, 1999.

[11] Haddad N. I., Bogyo T. P. and Muehlbauer F. J, Genetic variance of six agronomic characters in three lentil (lens culinaris medic) crosses," Euphytica, (31). 113-120,1982.

[12] Laghetti G., Pignone D., and Sonnante G., "Statistical Approaches to Analyse Gene Bank Data Using a Lentil Germplasm Collection as a Case Study,” Agriculture Conspectus Scientifics, (73). 175181, 2008.

[13] Laumont P., et Chevassus A. : Note sur l'amélioration de la lentille en Algérie. Ann. Ins. Agr. des services de recherche et expérimentation agricole de l'Algérie, Tome II.Juil.1960.35p.

[14] Muehlbauer, F.J., Cubero, J.I. and Summerfield, R.J. "Lentil (Lens culinaris Medic.),” In: Summerfield, R.J. and Roberts, E.H. (eds) Grain Legume Crops. Collins, London, UK, 266-311. 1985.

[15] Piergiovanni A.R., "The evolution of lentil (Lens culinaris Medik.) cultivation in Italy and its effects on the survival of autochthonous populations,” Genetic Resources and Crop Evolution (47). 305314, 2000.

[16] Rashmi Vamil A.U.H., and Agnihotri R.K., "Effect of Osmotic Stress (PEG) on Germination and Seedling Survival of Lentil (Lens culinaris MEDIK.),” Research Journal of Agricultural Sciences, 1 (3). 201-204,2010.

[17] Sultana T., and Ghafoor A., "Botanical and molecular evidences of landraces from the germplasm exclusively collected from Baluchistan, a centre of diversity for Lens culinaris,” African Journal of Biotechnology 8 (20). 5310-5315, October 19, 2009.

[18] Toklu F., Tuba B., and Karaköy T., "Agro-morphological characterization of the Turkish lentil landraces," African Journal of Biotechnology 8 (17), [Online]. Available at http://www.academicjournals.org/AJB/. [Accessed, 2009].

[19] Tyagi S. D., and Khan M. H., "Studies on genetic variability and interrelationship among the different traits in Microsperma lentil (Lens culinaris Medik)," Journal of Agricultural Biotechnology and Sustainable Development 2 (1) Available online: http://www.academicjournals.org/JABSD 